\title{
Business Education in Dermatology Residency: A Survey of Program Directors
}

\author{
James Randall Patrinely Jr, MD, MBA; Anna K. Dewan, MD, MHS
}

\section{PRACTICE POINTS}

- In our survey of dermatology program directors, most felt inclusion of business education in residency training was important.

- Approximately half of the dermatology programs that responded to our survey offer business training to their residents.

- Economics and finance, management, and health care policy were the most important topics identified to include in a business curriculum for dermatology residents.
With the rising cost of health care in the United States and an increasingly competitive market, dermatology residents would benefit from business training. We constructed an 8-part questionnaire for dermatology program directors (PDs) to determine the current perceptions of and resources available for business education. Of the 139 surveys distributed, 35 were completed (25.2\%). Approximately one half of the respondents said their programs offered business training, primarily through seminars or lectures. Most PDs felt business education during residency was important and that programs should implement more training. The most important topics identified for inclusion in a business curriculum were economics or finance, management, and health care policy or government. Our survey identified a gap between the perceived importance and current supply of business education during dermatology residency training. Future efforts should aim to develop a standardized, dermatology-specific curriculum that is readily available to all programs and residents.

Cutis. 2021;108:E17-E19.

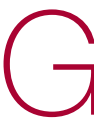
lobally, the United States has the highest percapita cost of health care; total costs are expected to account for approximately $20 \%$ of the nation's gross domestic product by $2025 .^{1}$ These rising costs have prompted residency programs and medical schools to incorporate business education into their curricula. ${ }^{2-5}$ Although medical training is demanding-with little room to add curricular components-these businessfocused curricula have consistently received positive feedback from residents. ${ }^{5,6}$

In dermatology, more than $50 \%$ of residents opt to join a private practice upon graduation. ${ }^{7}$ In the United States, there also is an upward trend of practice acquisition and consolidation by private equity firms. Therefore, dermatology trainees are uniquely positioned to benefit from business education to make well-informed decisions about joining or starting a practice. Furthermore, whether in a private or academic setting, knowledge of foundational economics, business strategy, finance, marketing, and health care policy can equip dermatologists to more effectively advocate for local and national policies that benefit their patient population. ${ }^{7}$

We conducted a survey of dermatology program directors (PDs) to determine the availability of and perceptions regarding business education during residency training.

\section{Materials and Methods}

Institutional review board (Vanderbilt University Medical Center, Nashville, Tennessee) approval was obtained. The survey was distributed weekly during a 5-week period from July 2020 to August 2020 through the Research Electronic Data Capture survey application (www.project-redcap.org). Program director email addresses were obtained through the Accreditation Council for Graduate Medical Education (ACGME) program list. A PD was included in the survey if they were employed by an accredited US osteopathic or allopathic

Dr. Patrinely is from Vanderbilt University School of Medicine, Nashville, Tennessee. Dr. Dewan is from the Department of Dermatology, Vanderbilt University Medical Center, Nashville. 
program and their email address was provided in the ACGME program list or on their program's faculty web page; a PD was excluded if an email address was not provided in the ACGME program list or on their program's faculty web page.

The 8-part questionnaire was designed to assess the following characteristics: details about the respondent's residency program (institutional affiliation, number of residents), the respondent's professional background (number of years as a PD, business training experience), resources for business education provided by the program, the respondent's opinion about business education for residents, and the respondent's perception of the most important topics to include in a dermatology curriculum's business education component, which included economics/finance, health care policy/government, management, marketing, negotiation, private equity involvement in health care, business strategy, supply chain/operations, and technology/product development. Responses were kept anonymous. Categorical and continuous variables were analyzed with medians and proportions.

\section{Results}

Of the 139 surveys distributed, 35 were completed and returned (response rate, 25.2\%). Most programs were university-affiliated $(71.4 \%)$ or communityaffiliated $(22.9 \%)$. The median number of residents was 12. The respondents had a median of 5 years' experience in their role. Most respondents $(65.7 \%)$ had no business training, although $20.0 \%$ had completed undergraduate business coursework, and $8.6 \%$ had attended formal seminars on business topics; $5.7 \%$ were self-taught on business topics.

Business Education Availability-Approximately half $(51.4 \%)$ of programs offered business training to residents, primarily through seminars or lectures (94.4\%) and take-home modules (16.7\%). None of the programs offered a formal gap year during which residents could pursue a professional business degree. Most respondents thought business education during residency was important $(82.8 \%)$ and that programs should implement more training $(57.1 \%)$. When asked whether residents were competent to handle business aspects of dermatology upon graduation, most respondents disagreed somewhat $(22.9 \%)$ or were neutral $(40.0 \%)$.

Topics for Business Education-The most important topics identified for inclusion in a business curriculum were economics or finance $(68.6 \%)$, management $(68.6 \%)$, and health care policy or government $(57.1 \%)$. Other identified topics included negotiation $(40.0 \%)$, private equity involvement in health care $(40.0 \%)$, strategy $(11.4 \%)$, supply chain or operations (11.4\%), marketing (2.9\%), and technology $(2.9 \%)$.

\section{Comment}

Residency programs and medical schools in the United States have started to integrate formal business training into their curricula; however, the state of business training in dermatology has not been characterized. Overall, this survey revealed largely positive perceptions about business education and identified a demand for more resources.

Whereas most PDs identified business education as important, only one half $(51.4 \%)$ of the representative programs offered structured training. Notably, most PDs did not agree that graduating residents were competent to handle the business demands of dermatology practice. These responses highlight a gap in the demand and resources available for business training.

Identifying Curricular Resources-During an already demanding residency, additional curricular components need to be beneficial and worthwhile. To avoid significant disruption, business training could take place in the form of online lectures or take-home modules. Most programs represented in the survey responses had an academic affiliation and therefore commonly have access to an affiliated graduate business school and/or hospital administrators who have clinical and business training.

Community dermatologists who own or run their own practice also are uniquely positioned to provide residents with practical, dermatology-specific business education. Programs can utilize their institutional and local colleagues to aid in curricular design and implementation. In addition, a potential long-term solution to obtaining resources for business education is to coordinate with a national dermatology organization to create standardized modules that are available to all residency programs.

Key Curriculum Topics-Our survey identified the most important topics to include in a business curriculum for dermatology residents. Economics and finance, management, and health care policy would be valuable to a trainee regardless of whether they ultimately choose a career in academia or private practice. A thorough understanding of complex health care policy reinforces knowledge about insurance and regional and national regulations, which could ultimately benefit patient care. As an example, the American Academy of Dermatology outlines several advocacy priorities such as Medicare reimbursement policies, access to dermatologic care through public and private insurance, medication access and pricing, and preservation of private practice in the setting of market consolidation. Having a better understanding of health care policy and business could better equip dermatologists to lead these often business-driven advocacy efforts to ultimately improve patient care and advance the specialty. ${ }^{8}$

Limitations-There were notable limitations to this survey, primarily related to its design. With a $25 \%$ response rate, there was the potential for response and selection biases; therefore, these results might not be generalizable to all programs. In addition, views held by PDs might not be consistent with those of other members of the dermatology community; for example, surveying 
residents, other faculty members, and dermatologists in private practice would have provided a more comprehensive characterization of the topic.

\section{Conclusion}

This study assessed residency program directors' perceptions of business education in dermatology training. There appears to be an imbalance between the perceived importance of such education and the resources that are available to provide it. More attention is needed to address this gap to ensure that dermatologists are prepared to manage a rapidly changing health care environment. Results of this survey should encourage efforts to establish (1) a standardized, dermatology-specific business curriculum and (2) a plan to make that curriculum accessible to trainees and other members of the dermatology community.

\section{REFERENCES}

1. Branning G, Vater M. Healthcare spending: plenty of blame to go around. Am Health Drug Benefits. 2016;9:445-447.

2. Bayard M, Peeples CR, Holt J, et al. An interactive approach to teaching practice management to family practice residents. Fam Med. 2003;35:622-624.

3. Chan S. Management education during radiology residency: development of an educational practice. Acad Radiol. 2004;11:1308-1317.

4. Ninan D, Patel D. Career and leadership education in anesthesia residency training. Cureus. 2018;10:e2546.

5. Yu-Chin R. Teaching administration and management within psychiatric residency training. Acad Psychiatry. 2002;26:245-252.

6. Winkelman JW, Brugnara C. Management training for pathology residents. II. experience with a focused curriculum. Am J Clin Pathol. 1994;101:564-568.

7. Tan S, Seiger K, Renehan $\mathrm{P}$, et al. Trends in private equity acquisition of dermatology practices in the United States. JAMA Dermatol. 2019;155:1013-1021.

8. Academy advocacy priorities. American Academy of Dermatology website. Accessed August 11, 2021. www.aad.org/member/advocacy/priorities 